\title{
USABILITY TESTING PADA SISTEM TRACER STUDY UNDIKSHA MENGGUNAKAN METODE HEURISTIC EVALUATION
}

\author{
I Made Arya Dwi Saputra1), I Made Ardwi Pradnyana'), Nyoman Sugihartini ${ }^{3)}$ \\ ${ }^{1}$ Fakultas Teknik dan Kejuruan, Universitas Pendidikan Ganesha \\ Email: aryadwisaputra60@gmail.com, ardwi.pradnyana@undiksha.ac.id², sugihartini@undiksha.ac.id³
}

\begin{abstract}
ABSTRAK
Tujuan dari penelitian ini adalah untuk menganalisis tingkat usability sistem tracer study Undiksha yang diukur menggunakan metode Heuristic Evaluation dengan menggunakan 10 variabel usability untuk menentukan rancangan layout sistem yang memenuhi kriteria usability. Sampel dalam penelitian ini terdiri dari 20 responden alumni Undiksha. Teknik penentuan sampel menggunakan proportionate starafied random sampling sebagai teknik pengambilan data. Hasil penelitian menunjukkan tingkat usability sistem tracer study Undiksha sebesar $60 \%$ yang termasuk dalam kategori tinggi. Dari hasil analisis kuisioner yang didapat hasil bahwa layout sistem tracer study Undiksha sudah mampu memenuhi kriteria usability sebuah sistem informasi. Sehingga dalam penelitian ini rekomendasi perbaikan berdasarkan hasil kuisioner yang memiliki persentase rendah dan berpedoman pada panduan $\mathrm{HCl}$ perbaikan layout. Perbaikan lebih difokuskan pada kejelasan informasi yang disajikan masih sedikit dan kurang update, adanya bantuan yang muncul tepat waktu saat terjadi error, penyajian submenu dan ikon-ikon yang konsisten, adanya keterangan pada link, dokumentasi yang lengkap, dan adanya menu bantuan untuk mempermudah pengguna dalam mencari solusi jika terdapat kesalahan saat mengakses sistem.
\end{abstract}

Kata kunci: usability, heuristic evaluation, tracer study Undiksha

\begin{abstract}
The purpose of this study was to analyze the level of usability system tracer study Undiksha measured using the Heuristic Evaluation method by using 10 usability variables to determine the design of the system layout that meets the usability criteria. The sample in this study consisted of 20 Undiksha alumni respondents. The sampling technique uses proportionate standard random sampling as a data collection technique. The results showed that the level of Undiksha usability system tracer study of $60 \%$ was included in the high category. From the results of the questionnaire analysis, the results of the Undiksha tracer study system layout have been able to meet the usability criteria of an information system. So in this study the recommendations for improvement are based on the results of the questionnaire which has a low percentage and is guided by the $\mathrm{HCl}$ guidelines for layout improvements. Improvements are focused more on the clarity of the information presented is still a little and less updated, there is assistance that appears on time when an error occurs, the presentation of submenus and consistent icons, information on links, complete documentation, and the help menu to facilitate users in find a solution if there is an error accessing the system.
\end{abstract}

Keywords: usability, heuristic evaluation, Undiksha tracer study

\section{PENDAHULUAN}

Perkembangan teknologi yang semakin pesat berpengaruh terhadap bebagai sektor kehidupan manusia. Kehadirannya telah memberikan dampak yang cukup besar terhadap kehidupan manusia dalam berbagai aspek dan dimensi. Salah satu aspek yang mendapat dampak dari perkembangan teknologi yaitu aspek pendidikan. Contoh penerapan perkembangan teknologi pada jenjang pendidikan tinggi yaitu Tracer Study. Tujuan utama dari tracer study adalah untuk memperoleh informasi mengenai lulusan yang sudah bekerja dan belum bekerja. Selain itu, tracer study berfungsi untuk mengetahui hasil pendidikan yang diaplikasikan didunia kerja serta transisi dari dunia pendidikan ke dunia usaha dan 
industri. Melalui tracer study penyelenggara pendidikan dapat mengetahui mutu layanan program melalui penilaian para alumni. Disamping itu, penyelenggara pendidikan mampu memperbaiki dan meningkatkan kualitas layanannya.

Salah satu universitas yang menerapkan tracer study yaitu Universitas Pendidikan Ganesha (Undiksha). Undiksha berada di Kabupaten Buleleng, Provinsi Bali. Undiksha merupakan institusi pendidikan tinggi yang menccetak sumber daya manusia dalam bidang kependidikan ataupun non kependidikan. Dalam bidang kependidikan, undiksha merupakan suatu institusi yang paling banyak mencetak tenaga pendidik di Bali. Visi Undiksha adalah menjadi universitas unggulan berlandaskan falsafah Tri Hita Karana.

Berdasarkan hasil wawancara dengan alumni pada masing-masing fakultas di Undiksha, mereka mengatakan sistem tracer study Undiksha sangat penting untuk mengetahui perkembangan dari lulusan dan juga untuk memberikan informasi kepada lembaga mengenai perkembangan pekerjaan yang telah alumni dapatkan. Namun mereka juga memiliki hambatan saat menggunakan sistem tracer study Undiksha. mereka mengatakan masih adanya ketidakjelasan antara pernyataan dan pertanyaan dalam form pengisian instrumen, desain yang kurang menarik,komponen yang disajikan kurang lengkap, buffering saat mengakses sistem tracer study karena banyak yang mengakses. Ini membuat para pengguna pemula kebingungan dan harus mempelajari ulang menggunakan sistem. Hal ini berdampak pada penurunan produktivitas, meningkatkan frustasi dan kerugian lainnya. Dari beberapa reponden yang telah mengisi angket awal, 1 alumni memberikan penilaian sangat nyaman, 3 alumni memberikan penilaian nyaman, dan 4 alumni memberikan penilaian cukup terhadap kenyamanan mereka saat menggunakan sistem tracer study Undiksha.

Usability adalah suatu istilah yang digunakan untuk menandakan bahwa user dapat mempekerjakan alat tertentu atau objek tertentu dengan mudah dalam rangka mencapai tujuan tertentu. Menurut [1] usability sebagai suatu pengalaman pengguna dalam berinteraksi dengan aplikasi atau situs web sampai pengguna dapat mengoperasikannya dengan mudah dan cepat. [1] juga merumuskan faktor-faktor penyebab pentingnya website memiliki aspek usability, di antaranya adalah kebiasaan atau perilaku pengguna yang mengakses website, banyak pengguna yang tidak dapat menerima design website yang buruk dan mau meluangkan waktu untuk mempelajari suatu website. Atau dengan kata lain, pengguna sangat ingin segera mengerti dengan seketika (instant), atas apa yang disajikan dalam suatu website.[2]

Dalam metode usability, terdapat beberapa teknik yang dapat digunakan. Teknik yang digunakan dalam penelitian ini yaitu Heuristic Evaluation (HE). HE merupakan metode untuk mengukur sejauh mana problem usability (kegunaan) sebuah perangkat lunak dalam desain antar muka. Identifikasi masalah usability ini berada di bidang interaksi manusia dan komputer. Penggunaan HE lebih dikaitkan dengan pemberian umpan balik dari para pengguna kepada para pengembang perangkat lunak sejauh mana antar muka dikembangkan kompatibel dengan kebutuhan dan preferensi pengguna tuju. Pada dasarnya HE adalah suatu kegiatan dimana para ahli meneliti suatu interface dan mengevaluasi tiap elemen dari interface yang berdasar pada daftar prinsip usabilitas yang diterima secara heuristic. Menggunakaan metode ini pada tahap sebelum pengujian langsung oleh pengguna akan mengurangi jumlah dan tingkat keparahan atau kesalahan desain. HE adalah metode yang sangat tepat untuk menganalisis usability dalam hal User Interface Design (UID). Metode ini memiliki keunggulan seperti mudah dan cepat dalam proses evaluasi, menggunakan peraturan yang telah diuji untuk dapat menemukan masalah usability. Namun pada metode HE juga memiliki kelemahan diantaranya mahalnya membayar para ahli dan kemungkinan para ahli bukan pengguna yang potensial. HE adalah cara mengevaluasi yang cukup terpercaya. [3] mengembangkan metode ini berdasarkan pengalaman sebagai pengajar dan konsultan dalam hal teknik kenyamanan pengguna website selama beberapa tahun. Pada penelitian ini peneliti memilih metode HE, karena HE mampu menemukan atau menentukan masalah usability yang muncul [4]

\section{METODE}

1. Jenis Penelitian

Jenis penelitian usability testing pada Sistem Tracer Study Undiksha adalah penelitian survei berbasis pengguna, sedangkan metodenya adalah deskriptif analitis. Penelitian ini menganalisis secara deskriptif mengenai evaluasi pengguan sistem tracer study Undiksha yang ditinjau dari aspek usability yang didasari pada fakta yang terjadi [5].

2. Lokasi dan Waktu Penelitian

Lokasi penelitian merupakan tempat dimana penelitian akan dilakukan. Penelitian ini dilaksanakan di Undiksha Subjek yang diteliti adalah alumni Undiksha waktu pelaksanaan penelitian ini adalah tahun ajaran 2018-2019. 


\section{Prosedur Penelitian}

Prosedur penelitian merupakan langkah-langkah yang ditempuh dalam melakukan suatu penelitian, untuk mendapatkan infomasi yang dapat menjawab pertanyaan peneliti. Prosedur penelitian dilaksanakan untuk dapat mengungkap secara tuntas terkait permasalahan yang diajukan dalam penelitian. Adapun prosedur penelitian disajikan pada gambar 1.

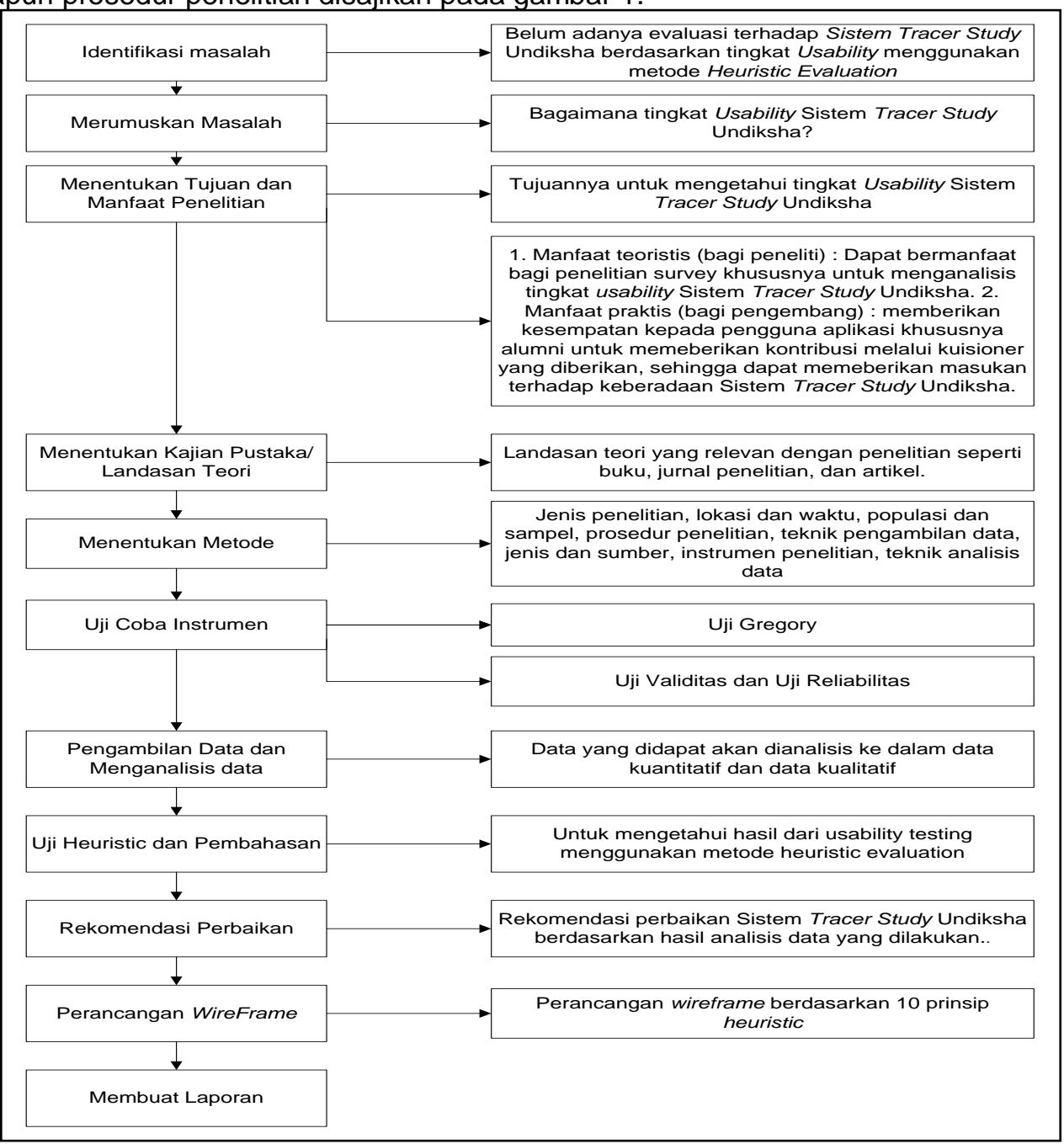

Gambar 1. Prosedur Penelitian

\section{Sampel Penelitian}

Teknik pengambilan sampel yang digunakan dalam penelitian ini adalah teknik Proportionate Stratifed Random Sampling. Dalam buku Usability Testing For Survery Research yang ditulis oleh [6] menjelaskan bahwa 15 orang responden dibutuhkan untuk mengidentifikasi seluruh permasalahan usability. Dengan 8 orang responden dapat mengidentifikasi sekitar 95\% permasalahan usability. Sumber lain ditemukan dalam penelitian [7] Quatitative Study : "How Many User to Test" dimana [7] mengungkapkan sebuah hasil penelitian kuantitatif disarankan menggunakan 20 responden, hal ini mengacu pada hasil penelitiannya dimana pengujian usability dengan 20 responden akan menghasilkan hasil yang tidak jauh berbeda sehingga dengan jumlah kecil dapat mengurangi biaya dan waktu yang berlebihan. Jumlah responden menurut [7] disajikan pada gambar 2. 


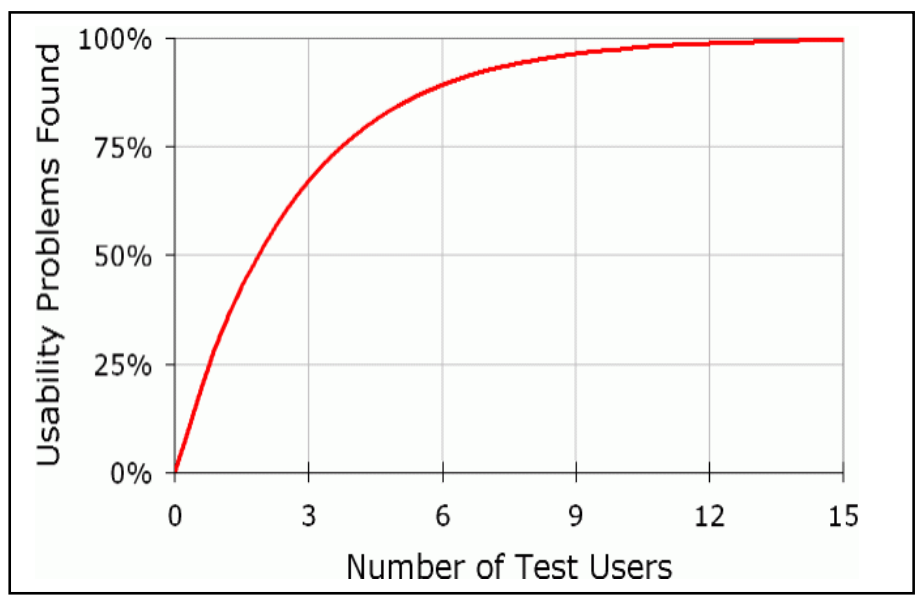

Gambar 2. Grafik Masalah Kegunaan

5. Teknik Pengumpulan Data :

Teknik pengumpulan data yang digunakan dalam penelitian ini adalah :

a. Dokumentasi

Metode dokumentasi yaitu salah satu cara mencari data mengenai hal-hal atau variabel yang berupa catatan, transkrip, buku, surat kabar, majalah, prasasti, dan sebagiannya [8]. Pada penelitian ini, peneliti menggunakan dokumentasi sebagai sarana untuk mendapatkan data yang diinginkan. Dokumentasi dalam penelitian ini berupa data jumlah alumni di Undiksha yang diperoleh dari wawancara, dan kuisioner.

b. Kuisioner

Kuisioner merupakan teknik pengumpulan data yang dilakukan dengan cara memberi seperangkat pertanyaan atau pernyataan tertulis kepada responden untuk dijawabnya [9]. Cara pengumpulan data dengan menggunakan daftar isian atau daftar pertanyaan yang telah disiapkan dan disusun sedemikian rupa sehingga calon responden hanya tinggal mengisi atau menandainya dengan mudah dan cepat. Kuesioner dalam penelitian ini merupakan kumpulan pertanyaan dalam penggunaan sistem Tracer Study Undiksha terkait dengan usability yang disebar ke sampel penelitian.

6. Jenis Data

Jenis data dalam penelitian ini terdiri dari data kualitatif dan kuantitatif.

a. Data kualitatif dalam penelitian ini adalah kutipan atau referensi dari jurnal penelitian yang terkait, artikel dan buku

b. Data kuantitatif dalam penelitian ini adalah hasil yang didapatkan dari penyebaran kusioner.

7. Sumber Data

Sumber data dalam penelitian ini terdiri dari data primer dan data skunder.

a. Data primer dalam penelitian ini adalah hasil survey terhadap terhadap responden dengan menggunakan instrumen kuisioner (angket)

b. Data skunder dalam penelitian ini didapatkan dari artikel, buku dan literatur lainnya yang relevan dengan penelitian.

8. Instrumen Penelitian

Dalam penelitian ini, instrumen yang digunakan adalah dalam bentuk kuisioner (angket)

9. Uji Coba Instrumen

Pada uji coba instrumen dilakukan pengujian terhadap item-item pernyataan yang terdapat pada kuisioner yaitu menggunakan uji gregory, uji validitas dan reliabilitas.

\section{Teknik Analisis Data}

Analisis data adalah proses mencari dan menyusun data yang diperoleh secara sistematis, dengan cara mengorganisasikan data ke dalam kategori, menjabarkan ke dalam unit-unit, melakukan sintesa, menyusun ke dalam pola, memilih mana yang penting dan yang akan dipelajari, serta membuat kesimpulan sehingga mudah dipahami oleh diri sendiri maupun orang lain [9]. Dalam 
penelitian ini menggunakan analisis kuantitatif dan kualitatif dan analisis kesuksesan. Analisis kuantitatif bertujuan untuk memperoleh data berupa angka [10]. Analisis kuantitatif juga bertujuan untuk memperoleh presentase dari hasil kuisioner yang nantinya akan dianalisis secara deskriptif. Hasil perhitungan persentase digunakan skala sebagai pedoman pendeskripsian usability sistem tracer study Undiksha. setelah didapatkan persentase jawaban responden selanjutnya diberikan penafsiran atau penilaian terhadap hasil penelitian. Peneliti menggunakan metode penafsiran seperti tabel 1 berikut :

Tabel 1. Kategori Nilai Persentase

\begin{tabular}{lll}
\hline NO. & $\begin{array}{l}\text { PERSENTASE } \\
\text { BATAS INTERVAL }\end{array}$ & $\begin{array}{l}\text { KATEGORI } \\
\text { PENILAIAN }\end{array}$ \\
\hline 1 & $0-20 \%$ & Sangat rendah \\
2 & $21-40 \%$ & Rendah \\
3 & $41-60 \%$ & Sedang \\
4 & $61-80 \%$ & Tinggi \\
5 & $81-100 \%$ & Sangat Tinggi \\
\hline
\end{tabular}

\section{HASIL DAN PEMBAHASAN}

Penelitian ini mengumpulkan hasil jawaban kuisioner dari 20 alumni sebagai responden. Deskripsi data berisi rata-rata persentase jumlah responden yang meliputi rata-rata persentase responden yang memilih pilihan sangat setuju (SS), setuju (S), kurang setuju (KS), tidak setuju (TS) dan untuk mengukur kategori tingkat kegunaan dari setiap indikator yaitu Visibility Match Between System and The Real World, User Control ad Freedom, Consistency and Standards, Recognition Rather than Recall, Flexibility and Efficiency of Use, Design, Recovery and System dan Help and Documentation. Dari seluruh sampel penelitian yang telah ditentukan, maka didaptkan hasil persentase pada masingmasing variable metode heuristic evaluation.

1. Hasil Uji Gregory

Perhitungan uji validitas isi dilakukan dengan formula Gregory dengan melibatkan [7]2 orang pakar. Hasil penilaian dari kedua pakar adalah 52 jawaban dinyatakan relevan jadi koefisien validitas isi instrumen yang diuji coba adalah 0.60 yang berkategori tinggi. Untuk instrumen yang dinilai tidak relevan telah diperbaiki sehingga semua instrumen dapat diujicobakan.

2. Hasil Uji Validitas

Pengujian validitas kosntruk untuk instrumen menggunakan rumus korelasi Pearson Product Moment. Dalam penelitian ini kuisioner telah diujicobakan ke 20 responden dilaur sampel penelitian. Hasil perhitungan menggunakan Microsoft Excel 2013 dan Aplikasi SPSS 20. Butir instrumen yang diujicobakan berjumlah 86 butir, 38 butir pertanyaan dinyatakan tidak valid dan 48 butir dinyatakan valid. Syarat minimum untuk dianggap suatu butir instrumen dinyatakan valid adalah nilai indeks validitasnya $>0.444$. Oleh karena itu semua pertanyaan yang memiliki korelasi dibawah 0.444 dinyatakan tidak valid [9] kemudian pertanyaan yang tidak valid, tidak diperbaiki dan tidak diujicoba kembali melainkan langsung dihilangkan.

3. Hasil Uji Reliabilitas

Uji reliabilitas dilakukan untuk menguji derajat konsistensi atau stabilitas instrumen dalam interval tertentu. Perhitungan uji reliabilitas menggunakan aplikasi SPSS 20. Berdasarkan uji coba instrumen kepada 20 orang responden, diperoleh hasil perhitungan reliabilitas menggunakan rumus Alpha Cronbach sebesar 0.882 dari 86 butir pertanyaan yang berkategori sangat tinggi.

4. Hasil Uji Heuristic

Berdasarkan gambar 3 dapat dilihat variabel-variabel pada metode heuristic evaluation ditinjau dari hasil jawaban alumni didapatkan variabel terbesar yaitu variable Flexibility and Efficiency of Use $90 \%$, kemudian variabel Design dengan persentase $77 \%$, variabel Recovery and System 72\%, variabel Prevention Error System, variabel Recognition Rather than Recall dan Help and documentation memiliki persentase yang sama sebesar $61 \%$, selanjutnya variabel Match Between System and real World dengan persentase sebesar $59 \%$, variabel Consistency and Standard sebesar 58\%, variabel User Control and Freedom sebesar $55 \%$, dan variablel Visibility yang memiliki persentase terkecil yaitu $48 \%$. 


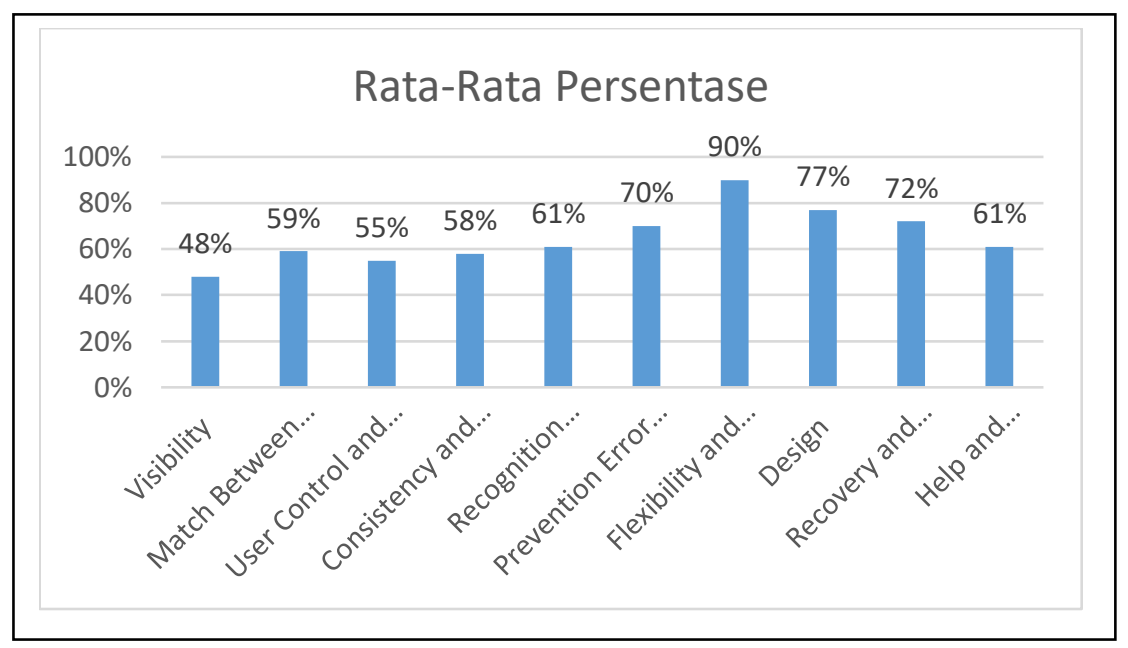

Gambar 3. Persentase Variabel Metode Heuristic Evaluation

Menurut hasil penelitian yang dilakukan peneliti, persentase variabel tertinggi yaitu Fleksibilitas dan Efisiensi yang meliputi penawaran bahasa yang berbeda dan sistem sesuai untuk screen reading, karena dilihat bahwa dari sistem tracer study Undiksha sudah dilengkapi dengan penawaran bahasa yang berbeda dan pada sistem tracer study Undiksha memang belum disajikan screen reading untuk mempermudah pengguna untuk membaca menu ataupun instrumen yang terdapat di sistem tracer study Undiksha. Jika dilihat dari variabel terkecil yaitu variabel visibility, berdasarkan jawaban dari responden alumni menyatakan bahwa informasi yang disajikan pada sistem tracer study Undiksha masih banyak yang kurang update misalkan pada menu pencarian pekerjaan informasi yang disajikan jarang diupdate oleh pihak pengelola sistem tracer study Undiksha.

Dari hasil rata-rata tiap variabel pada metode heurstic evaluation pada hasil penelitian kuisioner, maka dapat dicari rerata persentase tingkat usability sistem tracer study undiksha dengan kalkulasi dari 10 variabel. Dari kalkulasi hasil rata-rata 10 variabel metode heuristic, maka didapatkan hasil rata-rata tingkat usability sistem tracer study Undiksha, yaitu sebesar 59,6\% yang dibulatkan menjadi $60 \%$ maka tingkat persentase tersebut masuk ke dalam tingkat usability tinggi.

Kesimpulan yang didapat dari hasil kuisioner usability dengan menggunakan metode heuristic evaluation pada Sistem Tracer Study Undiksha yang diketahui bahwa layout sistem tracer study Undiksha dari hasil responden alumni sudah mampu memenuhi kriteria usability sebuah sistem informasi. Namun dari informasi yang disajikan masih kurang lengkap dan kurang update. Sehingga dalam penelitian ini berdasarkan hasil kuisioner ,uji ahli dan berdasarkan ilmu $\mathrm{HCl}$ rekomendasi perbaikan layout akan lebih difokuskan pada SOP (Standar Operasional Prosedur) pelayanan informasi yang jelas, cepat dan tepat pada sistem agar informasi yang disajikan pada sistem lebih lengkap dan terbaru. Selain itu, diharapkannya pelayanan yang cepat jika terjadi permasalahan pada sistem seperti terjadinya error pada halaman sistem.

Dari hasil analisa kuisioner didapat hasil bahwa layout sistem tracer study Undiksha sudah mampu memenuhi kriteria usability sebuah sistem informasi. Sehingga dalam penelitian ini rekomendasi berdasarkan hasil kuisioner yang memiliki persentase rendah, dan didasarkan pada panduan $\mathrm{HCl}$ perbaikan layout lebih difokuskan pada penambahan informasi pada sistem tracer study Undiksha, terjadi bantuan saat terjadi error, perbedaan warna font antara judul dan deskripsi kalimat, adanya bantuan untuk mempermudah pengguna dalam mencari solusi jika terdapat kelasahan dalam mengakses sistem.

Tabel 2. Tabel Hasil Analisa Kuisioner

\begin{tabular}{lllll}
\hline NO & VARIABEL & INDIKATOR & KODE & TEMUAN PELANGGARAN \\
\hline 1 & Visibility & Kejelasan Informasi & A1 & $\begin{array}{l}\text { Informasi yang disajikan belum } \\
\text { lengkap }\end{array}$ \\
& Konsistensi & A2 & $\begin{array}{l}\text { Submenu yang disajikan kurang } \\
\text { konsisten dan kurang rapi }\end{array}$ \\
2 & $\begin{array}{l}\text { Match Between System } \\
\text { and Real World }\end{array}$ & Pemilihan Warna & B1 & $\begin{array}{l}\text { Warna yang dipilih tidak sesuai } \\
\text { dengan ekspektasi pada kode } \\
\text { warna }\end{array}$
\end{tabular}




\begin{tabular}{|c|c|c|c|c|}
\hline 3 & $\begin{array}{l}\text { User Control and } \\
\text { Freedom }\end{array}$ & Kemudahan Navigasi & $\mathrm{C} 1$ & $\begin{array}{l}\text { Pengguna bisa mengcopy data } \\
\text { menggunakan cursor }\end{array}$ \\
\hline 4 & $\begin{array}{l}\text { Consistency and } \\
\text { Standard }\end{array}$ & $\begin{array}{l}\text { Konsistensi Data dan } \\
\text { proses }\end{array}$ & D1 & $\begin{array}{l}\text { Data satu dengan data lainnya } \\
\text { tidak disajikan secara konsisten }\end{array}$ \\
\hline \multirow[t]{2}{*}{5} & $\begin{array}{l}\text { Recognition Rather } \\
\text { Than Recall }\end{array}$ & $\begin{array}{l}\text { Adanya Keterangan } \\
\text { Pada Link }\end{array}$ & E1 & Menambahkan link \\
\hline & & $\begin{array}{l}\text { Kejelasan } \\
\text { Penggunaan Bahasa, } \\
\text { Simbol dan Gambar }\end{array}$ & E2 & $\begin{array}{l}\text { Adanya symbol asing yang } \\
\text { digunakan }\end{array}$ \\
\hline 6 & $\begin{array}{l}\text { Prevention Error } \\
\text { System }\end{array}$ & $\begin{array}{l}\text { Pencegahan } \\
\text { Pengguna Dalam } \\
\text { Membuat Kesalahan }\end{array}$ & $\mathrm{F} 1$ & $\begin{array}{l}\text { Pencegahan pengguna dalam } \\
\text { membuat kesalahan }\end{array}$ \\
\hline 7 & $\begin{array}{l}\text { Flexibility and Efficiency } \\
\text { of Use }\end{array}$ & Screen Reading & G1 & $\begin{array}{l}\text { Sistem belum dilengkapi } \\
\text { dengan screen reading }\end{array}$ \\
\hline \multirow[t]{2}{*}{8} & Design & $\begin{array}{l}\text { Pemilihan Warna } \\
\text { Font dan Background }\end{array}$ & $\mathrm{H} 1$ & $\begin{array}{l}\text { Font dan background yang } \\
\text { digunakan tidak sesuai dengan } \\
\text { bidang informasi yang } \\
\text { disediakan }\end{array}$ \\
\hline & & Ukuran Font & $\mathrm{H} 2$ & $\begin{array}{l}\text { Ukuran font yang digunakan } \\
\text { belum sesuai }\end{array}$ \\
\hline 9 & Recovery and System & $\begin{array}{l}\text { Notifikasi Ketika Ada } \\
\text { Kesalahan }\end{array}$ & 11 & $\begin{array}{l}\text { Perlu adanya pemberitahuan } \\
\text { ketika adanya kesalahan }\end{array}$ \\
\hline \multirow[t]{2}{*}{10} & $\begin{array}{l}\text { Help and } \\
\text { Documentation }\end{array}$ & Dokumentasi & J1 & $\begin{array}{l}\text { Sistem belum menyediakan fitur } \\
\text { dokumentasi }\end{array}$ \\
\hline & & $\begin{array}{l}\text { Panduan Secara } \\
\text { Online }\end{array}$ & $\mathrm{J} 2$ & $\begin{array}{l}\text { Sistem belum menyediakan fitur } \\
\text { bantuan secara online. }\end{array}$ \\
\hline
\end{tabular}

Berdasarkan hasil analisa kuisioner didapat hasil bahwa layout sistem tracer study Undiksha sudah mampu memenuhi kriteria usability sebuah sistem informasi. Sehingga dalam penelitian ini rekomendasi perbaikan berdasarkan hasil kuisioner yang memiliki persentase rendah dan didasarkan pada panduan $\mathrm{HCl}$. Perbaikan layout lebih difokuskan pada penambahan informasi pada sistem tracer study Undiksha, terjadi bantuan saat terjadi error, perbedaan warna font antara judul dan deskripsi kalimat, adanya bantuan untuk mempermudah pengguna dalam mencari solusi jika terdapat kelasahan dalam mengakses sistem.

1. Rekomendasi Perbaikan Menu Dashboard

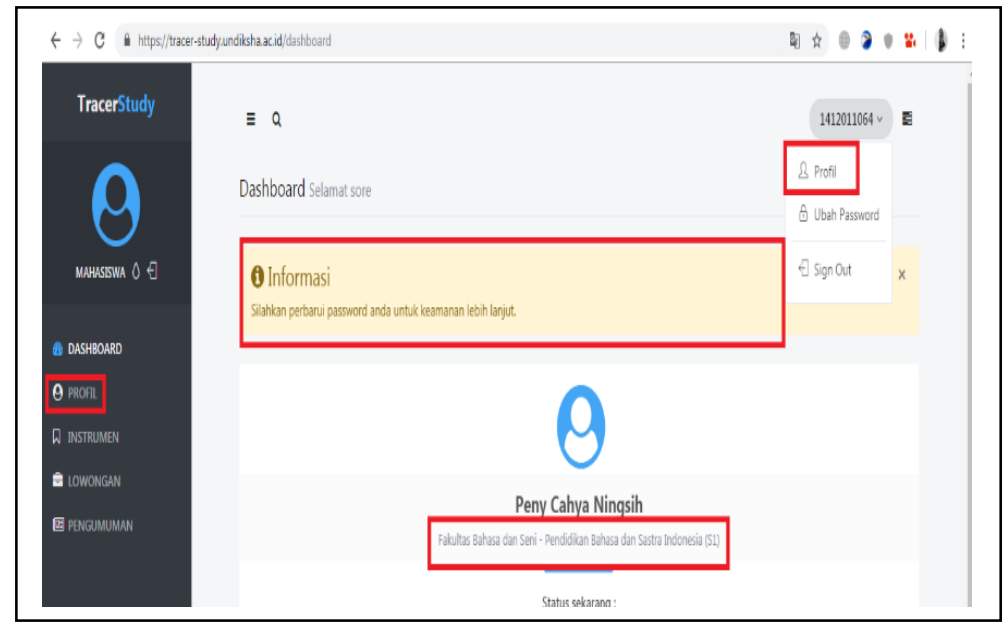

Gambar 4. Halaman Dashboard Sistem Tracer Study Undiksha 
Gambar 4 adalah tampilan halaman dashboard sistem tracer study Undiksha sebelum dilakukan perubahan. Adapun pelanggaran yang terdapat pada halaman ini adalah redudansi menu profil dan logout, ukuran font pada status user terlalu kecil dan menambahkan link. Adapun rancangan rekomendasi perbaikan pada halaman dashboard sistem tracer study Undiksha disajikan pada gambar 5 .

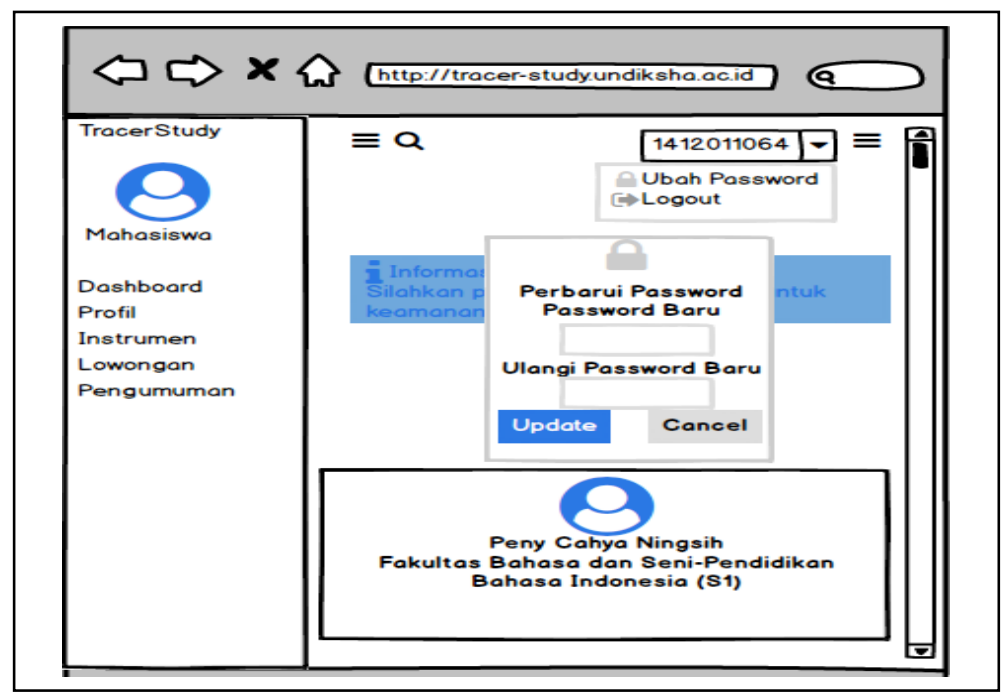

Gambar 5. Rekomendasi Perbaikan Tapilan Dashboard

Perubahan yang peneliti rekomendasikan serta penjelasan perubahan pada gambar 5 dijabarkan sebagai berikut :

a. Menghilangkan menu profil dan menu logout pada bagian menu utama. adanya redudansi tombol dengan fungsi yang sama berpotensi menyebabkan pengguna mengalami kebingungan merujuk pada tabel 2 kode A2. Hal tersebut juga berlawanan dari teori pada buku Research-Based Web Design \& Usability Guidelines yang menyebutkan untuk tidak menyediakan dua atau lebih cara dengan informasi yang sama pada satu halaman website. Maka dari itu peneliti menghilangkan salah satu menu profil dan menu logout.

b. Memperbesar ukuran font merujuk pada tabel 2 kode H2 yaitu agar berukuran 14 berdasarkan aturan dari buku Research-Based Web Design \& Usability Guidelines untuk menggunakan ukuran font setidaknya menggunakan font berukuran 12 . Pertimbangan ini juga dilakukan atas saran dari responden bahwa font yang digunakan dirasa masih terlalu kecil dan perlu diperbesar untuk kenyamanan pengguna sistem.

c. Rekomendasi selanjutnya yaitu menambahkan link merujuk pada tabel 2 kode E1, pertimbangan ini dilakukan atas saran dari responden. Sehingga pengguna tidak perlu melakukan proses yang terlalu panjang saat akan merubah password. Dan warna teks pada link sebaiknya menggunakan warna biru. Rekomendasi ini sesuai dengan buku Research-Based Web Design \& Usability Guidelines'

d. Rekomendasi selanjutnya yaitu menghilangkan simbol asing yang terdapat pada menu dashboard sistem tracer study Undiksha merujuk pada tabel 2 kode E2. Pertimbangan ini dilakukan atas saran dari responden, masih terdapat simbol asing pada menu dashboard agar meminimalisir kesalahan yang dilakukan oleh pengguna.

2. Rekomendasi Perbaikan Menu Profil 


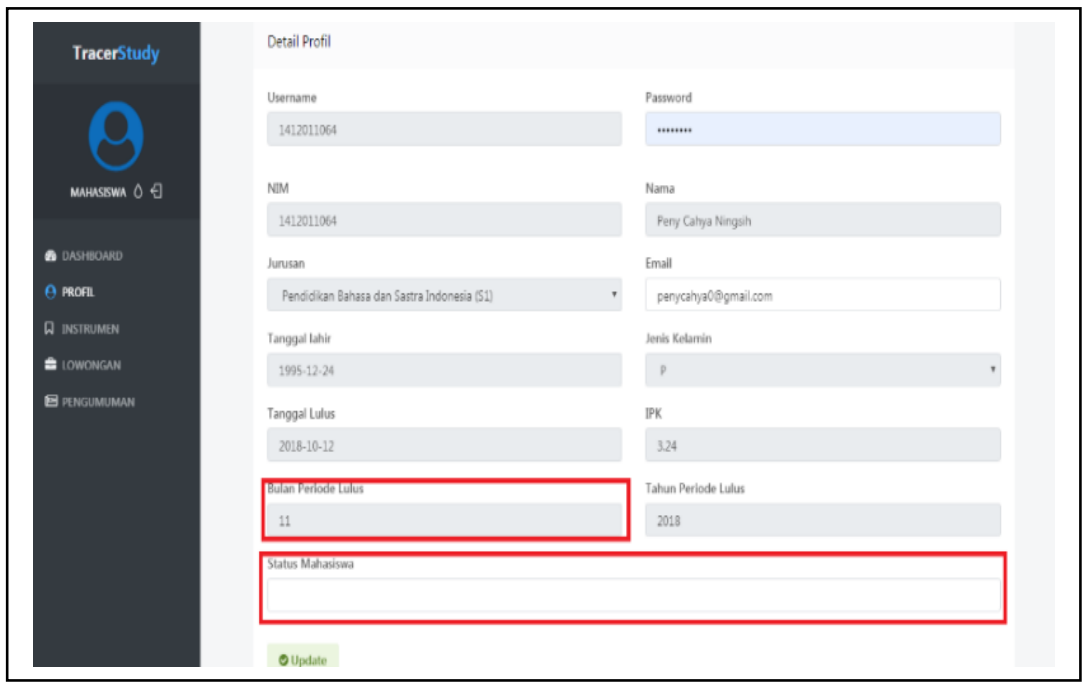

Gambar 6. Halaman Menu Profil

Gambar 6 merupakan tampilan pada Menu profil sebelum adanya perubahan. Adapun perbaikan yang peneliti tawarkan untuk laman ini yaitu menambahkan combo box dan menghilangkan menu status mahasiswa yang disajikan pada gambar 7

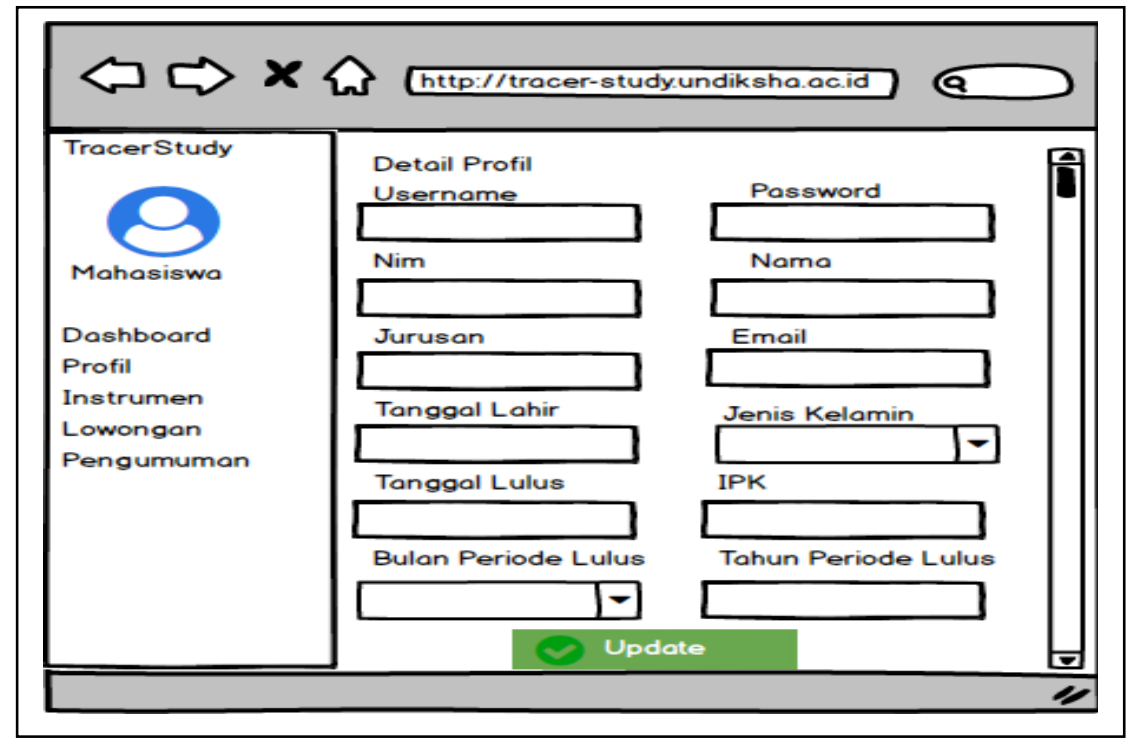

Gambar 7. Rekomendasi Perbaikan Menu Profil

Berdasarkan gambar 7 rancangan rekomendasi perbaikan yang peneliti lakukan adalah sebagai berikut :

Menambahkan combo box pada bulan periode lulus dan menghilangkan form status mahasiswa. mempermudah pengguna dalam memasukkan bulan periode lulus, sedangkan untuk status mahasiswa dihilangkan agar tidak membingungkan pengguna saat penginputan data. Hal ini jelas melanggar teori heuristic untuk pencegahan pengguna dalam membuat kesalahan merujuk pada tabel 2 kode F1.

\section{Rekomendasi Perbaikan Pada Menu Instrumen}




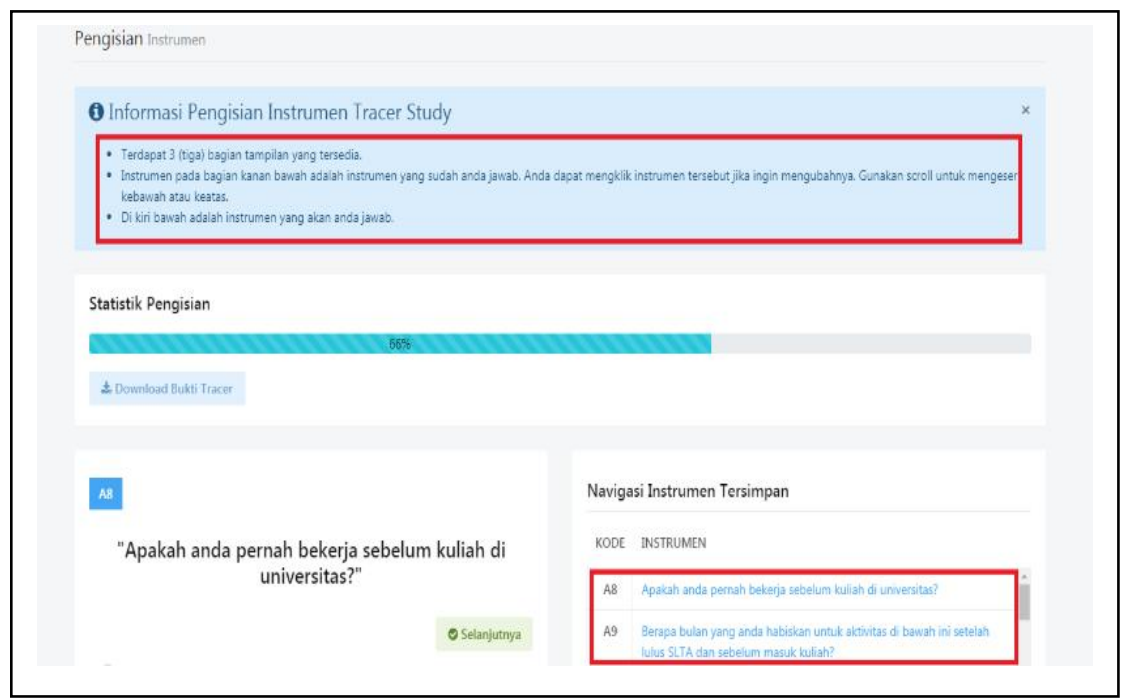

Gambar 8. Halaman Menu Instrumen

Gambar 8 merupakan tampilan pada menu instrumen sebelum adanya perubahan. Adapun pelanggaran yang terdapat pada halaman ini adalah font pada pemberitahuan pengisian instrumen terlalu kecil dan pemilihan warna font tidak sesuai. Disajikan pada gambar 9

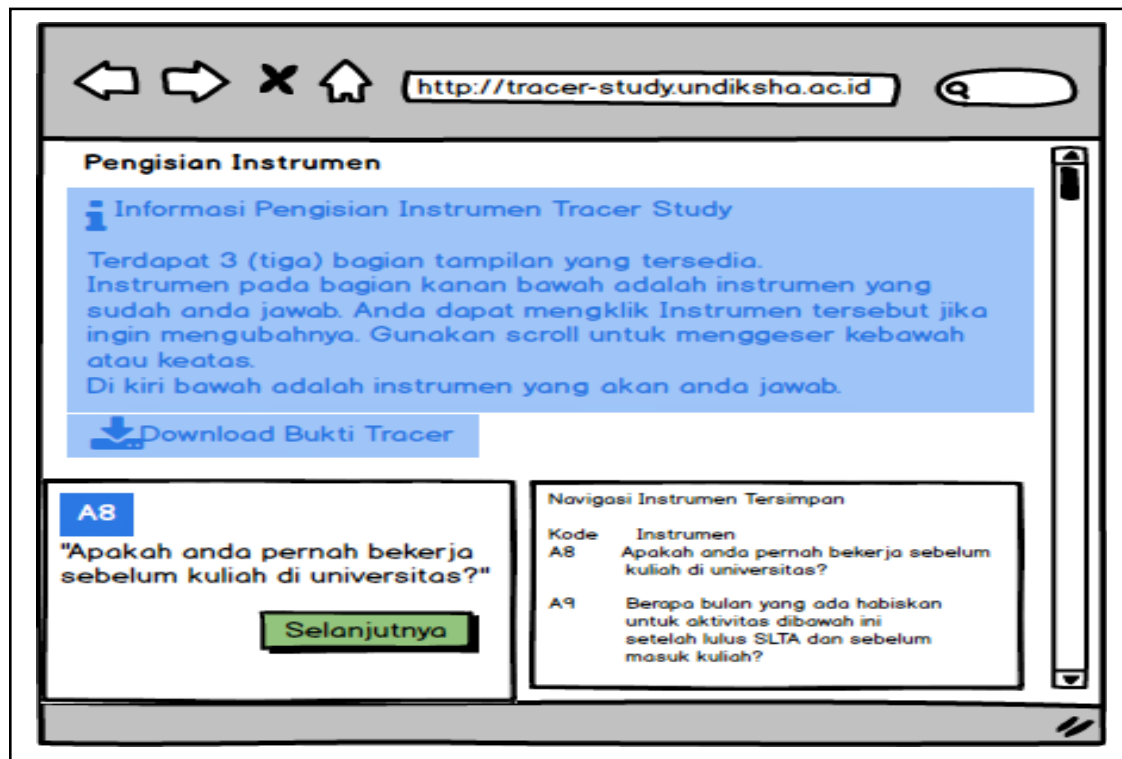

Gambar 9. Rekomendasi Perbaikan Menu Instrumen

Berdasarkan gambar 9 rancangan rekomendasi perbaikan peneliti lakukan adalah sebagai berikut :

a. Memperbesar ukuran font merujuk pada tabel 2 kode H2 yaitu agar berukuran 14 berdasarkan aturan dari buku Research-Based Web Design \& Usability Guidelines untuk menggunakan ukuran font setidaknya menggunakan font berukuran 12. Pertimbangan ini juga dilakukan atas saran dari responden bahwa font yang digunakan dirasa masih terlalu kecil dan perlu diperbesar untuk kenyamanan pengguna sistem.

b. Mengganti warna font dengan font yang lebih gelap merujuk pada tabel 2kode B1 yaitu, jika dibandingkan dengan wana sebelumnnya, font warna biru sangat dengan kolom yang berwarna putih sehingga font tidak begitu jelas terlihat. Rekomendasi ini berdasarkan aturan dari buku Research-Based Web Design \& Usability Guidelines yaitu orang akan membaca tulisan gelap $32 \%$ lebih cepat dari pada membaca tulisan terang. 


\section{SIMPULAN DAN SARAN}

Berdasarkan deskripsi data, hasil penelitian dan analisa usability kuisioner dengan menggunakan metode Heuristic Evaluation yang telah dibahas secara deskriptif, maka simpulan dari peneliti adalah terdapat 10 variabel yang digunakan dalam penelitian ini yang diambil dari metode Heuristic Evaluation, yaitu, Visibility, Match Between System and The Real World, User Control and Freedom, Consistency and Standard, Recognition Rather Than Recall, Prevention Error System, Flexibility and Efficiency of Use, Design, Recovery and System, Help and Documentation. Dari 20 responden didapatkan tingkat usability sistem tracer study Undiksha sebesar $60 \%$ yang masuk dalam kategori tinggi. Dari hasil analisa kuisioner didapat hasil bahwa layout sistem tracer study Undiksha sudah mampu memenuhi kriteria usability sebuah sistem informasi. Sehingga dalam penelitian ini rekomendasi berdasarkan hasil kuisioner yang memiliki persentase rendah dan panduan perbaikan layout didasarkan pada panduan $\mathrm{HCl}$. Rekomendasi perbaikan dalam penelitian ini difokuskan untuk mengubah tata letak layout halaman yang didasari hasil data penyebab kesalahan error pada pengguna. Selain itu berdasarkan hasil dan saran pengguna melalui hasil penyebaran kuisioner dan wawancara perbaikan pada sistem tracer study Undiksha dengan membuat Wifeframe pada halaman pemilihan warna, kejelasan informasi, menambahkan link, ukuran font.

Adapun saran yang dapat diajukan berkaitan dengan hasil penelitian ini adalah pada penelitian ini menggunakan metode Heuristic Evaluation untuk mengukur tingkat usability testing sistem tracer study Undiksha, disarankan agar menggunakan metode Cognitive Waltrough atau Think Alound sehingga menjadi tahu kekurangan dan kelebihan setiap metode pengujian usability testing yang ada.

\section{DAFTAR PUSTAKA}

[1] J. Nielsen, Designing Web Usability: The Practice of Simpicity. New Riders Publishing, 2000.

[2] P. Krisnayani, I. K. Arthana, and I. G. M Darmawiguna, "Analisa Usability Pada Website UNDIKSHA Dengan Menggunakan Metode Heuristic Evaluation," Kumpul. Artik. Mhs. Pendidik. Tek. Inform., vol. 5, no. 2, 2016.

[3] J. Nielsen, "10 Usability Heuristics for User Interface Design." N/g Nielsen Norman Group., 1994.

[4] M. Sulistiyono, "EVALUASI HEURISTIC SISTEM INFORMASI PELAPORAN KERUSAKAN LABORATORIUM UNIVERSITAS AMIKOM YOGYAKARTA," vol. Vol. 18 No, p. HIm. 37-43.

[5] S. Suryabrata, Metodelogi Penelitian. Jakarta: Pt. Rajagrafindo Persada., 2003.

[6] E. Geisen and J. R. Bergstrom, Usability Testing for Survey Research. Cambridge: Elsevier Inc, 2017.

[7] J. Nielsen, "Quantitative Studies: How Many Users to Test?," NN/g Nielsen Norman Group. p. 3, 2006.

[8] S. Arikunto, Manajemen Penelitian. Jakarta: Rineka Cipta, 2002.

[9] Sugiyono, Statistika untuk penelitian. Bandung: alfabeta., 2012.

[10] R. Bogdan, Kependidikan, Penelitian Kuantitatif Untuk. Boston: Allyn Dan Bocan, Inc., 1982. 